\title{
REFORMA CURRICULAR DOS CURSOS DE LICENCIATURA EM EDUCAÇÃO FÍSICA: CONTRIBUIÇÕES DOS PROFESSORES DAS REDES PÚBLICAS DE ENSINO*
}

\author{
Gabriel Humberto Muñoz ${ }^{*}$ \\ RéGis HenRiQue dos Reis SiLVA** \\ Tiago Soares Alves ${ }^{* * * *}$ \\ Danielle Barbosa Santos ${ }^{* * * *}$ \\ Ana Paula Fernandes Bertoldi ${ }^{* * * *}$
}

\section{RESUMO}

O objetivo deste artigo é analisar as novas Diretrizes Curriculares Nacionais para o Ensino Superior, especialmente, o estudo do processo de reforma curricular promovido para os cursos de Licenciatura em Educação Física. Assim, pretende-se contribuir para o debate sobre tais diretrizes no contexto da reforma desses cursos, a partir do estudo das representações de professores das redes públicas de ensino, relacionadas com seus saberes, a respeito de sua formação inicial e do seu exercício profissional.

PALAVRAS-CHAVE: políticas públicas - Diretrizes Curriculares Nacionais - teoria de currículo - educação física - formação de professores

\section{INTRODUÇÃO}

$\mathrm{D}$ esde sua criação, as Instituições de Ensino Superior (IES) são alvo de reformas políticas orientadas para se adaptarem aos interesses e demandas dos momentos sócio-históricos em que são implementadas. Tais reformas sempre entraram em conflito com os movimentos sociais que defendem uma educação pública, gratuita, laica e de qualidade, fora da lógica imposta pelo mercado globalizado. Esse conflito encontrase presente, também, no atual processo de reforma das Diretrizes

* Este artigo é parte de pesquisa de iniciação científica financiada pela Fundação de Amparo à Pesquisa do Estado de Minas Gerais, em convênio com Universidade Federal de Uberlândia, cujos resultados serão publicados integralmente na forma de livro pela EdUFU.

** Professor doutor da FAEFI/UFU, sócio efetivo do CBCE.

*** Professor mestre do CEPAE/UFG, sócio efetivo do CBCE.

**** Professor da ESEBA/UFU.

****** Graduandas da FAEFI/UFU. 
Curriculares Nacionais (DCN's) e, especialmente, no âmbito dos cursos de graduação para formação de professores do ensino básico. Dessa forma, o objetivo deste artigo é analisar as novas DCN's para o Ensino Superior, especialmente, o estudo do processo de reforma curricular promovido para os cursos de Licenciatura em Educação Física (LEF), bem como contribuir para o debate sobre tais diretrizes no contexto da reforma desses cursos, a partir do estudo das representações de professores das redes públicas de ensino, relacionadas com seus saberes a respeito da formação inicial e do exercício profissional.

A partir da promulgação, em 1996, da nova Lei de Diretrizes e Bases da Educação Nacional (LDBN), foi proposta uma profunda revisão de toda a tradição tecnicista construída em torno de um tipo de formação profissional ainda arraigada nas Universidades Públicas. Convém observar, dentre outros aspectos, que essa tradição ainda não conseguiu ser superada, ao mesmo tempo em que se constituiu forte organização burocratizada e hierarquizada do sistema universitário.

O paradigma de formação profissional, atualmente vigente nas Universidades Públicas, já se revelou inadequado para os desafios do mundo contemporâneo, dentro do qual, a graduação passou a representar a etapa inicial de um longo e amplo processo de formação continuada e permanente do futuro profissional.

Nesse sentido, a pesquisa que possibilitou a elaboração deste artigo justificou-se na medida em que se encontra em uma dimensão de trabalho docente que defende a realização de pesquisas, com perspectivas filosóficas e científicas capazes de oferecer subsídios para a melhoria do ensino dos cursos de graduação, fora dos traços autoritários e tecnicistas que os têm caracterizado, hegemonicamente.

\section{APONTAMENTOS SOBRE A IMPLEMENTAÇÃO DO ATUAL PROCESSO DE REFORMA CURRICULAR PARA O ENSINO SUPERIOR NO BRASIL}

Parte das origens desse debate pode ser encontrada nos anos 80, no âmbito da Associação Nacional pela Formação dos Profissionais da Educação (ANFOPE), cujas reflexões e críticas ganharam destaque também nas reuniões de associações que congregam profissionais da educação, tais como a Associação Nacional de Pós-Graduação e Pesquisa em Educação (ANPEd), o Fórum de Graduação (ForGRAD) e 
diversas outras associações profissionais e sindicatos que congregam essa esfera de trabalho.

Encontramos também indícios desse debate nos problemas enfrentados com a legislação vigente, as exigências provocadas pelas mudanças estruturais ocorridas no mundo do trabalho e às críticas à formação profissional promovida pelas instituições de ensino superior, a partir da metade dos anos 90, quando uma discussão em nível nacional foi desencadeada para debater essa problemática.

Estes debates confluíram no processo de reorganização institucional da educação nacional iniciada nos anos 90, a partir da criação do Conselho Nacional de Educação (CNE), em 1995, no governo Fernando Henrique Cardoso, o qual provocou e ainda provoca, no ensino superior, intensos debates sobre quais deveriam ser as novas normas reguladoras e as diretrizes orientadoras dos processos de formação profissional voltados para o século XXI.

Dentro do CNE, foi criada a Câmara de Educação Superior (CES) - Lei n. 9.131 de 1995, com a incumbência de deliberar sobre as diretrizes curriculares a serem propostas pelo Ministério de Educação e Cultura (MEC) para os cursos de graduação.

Como resultado, desencadeou-se o processo de construção de diretrizes curriculares para os cursos de graduação e contou com a participação da sociedade civil e das instituições públicas e privadas de ensino, garantindo-se especial atenção à formação superior de professores para os ensinos fundamental e médio.

A discussão sobre tais diretrizes trouxe à tona um debate relacionado com as diferentes concepções, abordagens e interesses subjacentes às práticas docentes e científicas da educação, os quais refletiram tanto a definição de determinados perfis profissionais, quanto a natureza das estruturas curriculares desejadas para promover a formação de professores no ensino superior, considerada ideal para o século XXI.

Importante ressaltar que a construção de tais diretrizes foi condicionada, pela legislação pertinente ao tema em questão, à LDBN, ao Plano Nacional de Educação (PNE) e a um conjunto de pareceres e resoluções emitidos pelo CNE, por meio de sua CES, desde 1997.

A elaboração das Diretrizes Curriculares para os Cursos de Graduação em Educação Física coube às comissões de especialistas vinculadas à Secretaria de Ensino Superior do MEC (SESu/MEC). Sua 
função foi sistematizar, debater e definir as propostas de Diretrizes Curriculares encaminhadas ao CNE para análise de mérito e decisões cabíveis (BRASIL/CNE/CES, 2004).

Entretanto, a construção das diretrizes foi permeada pela disputa de poder alavancada por segmentos da Educação Física que defendem concepções e práticas profissionais diferenciadas. Esta disputa continuou apesar da publicação das Diretrizes Nacionais para os Cursos de Graduação em Educação Física (2004), nos cursos de graduação, nos quais vêm travando-se, no nosso entendimento, dois tipos de confrontos.

$\mathrm{O}$ primeiro confronto encontra-se associado às divergências relacionadas com a possibilidade de dividir a formação inicial em graduação e licenciatura, em detrimento de um único curso denominado Licenciatura Ampliada. Aqueles que entendem a Educação Física como prática liberal vinculada à lógica do mercado, defendem a existência dessa divisão por avaliar que nem todos os profissionais da área precisarão de formação pedagógica, a qual considera-se específica (instrumental) para atuar nos sistemas formais de educação. Aspecto este que poderia, inclusive, diminuir a duração do curso de formação desses profissionais.

Além de discordar de tudo isso, os defensores da formação profissional numa perspectiva ampliada, dentro da qual encontramo-nos, consideram que a Educação Física, independentemente dos campos de atuação profissional que ela oferece, estabelece uma relação científica, pedagógica, técnica, ética, moral e política, que deve nortear o currículo educacional no ensino superior como um todo (TAFFAREL; LACKS, 2005).

$\mathrm{O}$ segundo confronto encontra-se relacionado às questões teóricas, políticas e ideológicas subjacentes às novas diretrizes curriculares: uma das vertentes entende que as DCN's foram fruto de um consenso possível entre aqueles que participaram da sua construção, ao passo que a outra vertente defende a idéia de que os avanços foram muito pequenos, uma vez que conceitos e diretrizes fundamentais relacionados à formação, permaneceram presos à lógica liberal da área da Educação Física.

Um desses conceitos refere-se, por exemplo, ao próprio objeto de estudo da Educação Física, o qual nas diretrizes curriculares continuou atrelado a um conceito que para os segmentos progressistas, tornou-se ultrapassado. Trata-se da velha noção de "movimento humano", cunha- 
da em detrimento de outros conceitos considerados mais avançados, tal como o de Cultura Corporal de Movimento ligado à corrente críticosuperadora da Educação Física, dentro do qual a idéia de formação humana compreende dimensões da existência humana, a saber: científica, pedagógica, técnica, ético-moral e política, em contraposição à concepção de competências incluídas no documento final das diretrizes curriculares para os cursos de Educação Física.

\section{REPRESENTAÇÕES SOBRE O COTIDIANO ESCOLAR DE UM CURSO DE LICENCIATURA EM EDUCAÇÃO FÍSICA: ANÁLISE DAS DIFICULDADES PARA REALIZAÇÃO DA REFORMA CURRICULAR}

Para contribuir com a reforma curricular dos cursos de LEF, buscamos subsídios no estudo das representações coletivas dos licenciados de Educação Física formados entre 1978 e 2002, que atuam em escolas das redes públicas de ensino de Uberlândia e Região, seguido do estudo das propostas que esses mesmos profissionais apontam para promover uma reformulação curricular orientada para melhoria da qualidade do curso de LEF.

As representações dos licenciados em Educação Física inquiridos foram obtidas mediante a aplicação de 39 questionários (semi-estruturado) nos meses de junho e agosto de 2005, durante a realização de um programa de formação continuada de professores das redes públicas de ensino de Uberlândia, promovido pela $40^{a}$. Superintendência de Ensino da Secretaria do Estado da Educação de Minas Gerais e o Núcleo de Estudos em Planejamento e Metodologias do Ensino da Cultura Corporal da Faculdade de Educação Física da Universidade Federal de Uberlândia (NEPECC/FAEFI/UFU).

Dos professores inquiridos $82,05 \%$ são do sexo feminino, 89,74\% do total cursaram a licenciatura na Faculdade de Educação Física da Universidade Federal de Uberlândia (FAEFI/UFU), 53,90\% têm idade igual ou acima de 40 anos, enquanto 38,40\% apresentam-se na faixa etária que varia de 25 a 39 anos. $12,80 \%$ iniciaram suas atividades profissionais no período compreendido entre 2000 e 2005 e $43,60 \%$ o fizeram entre 1980 e 1989.

No que diz respeito, aos locais e turnos de trabalho $58,82 \%$ trabalham em uma única escola e $41,18 \%$ em duas e do total dos 
entrevistados, $66,67 \%$ ministram aula nos turnos matutino e vespertino. Somente $03,03 \%$ dos professores mencionaram que trabalham no ensino noturno, porém associados aos turnos matutino e vespertino. E, finalmente, $71,43 \%$ dos entrevistados, encontram-se lotados em escolas de ensino fundamental, 4,08\% em escolas de ensino infantil, $18,37 \%$ em escolas de ensino médio e $6,12 \%$ dos inquiridos não responderam a essa questão.

\section{PRINCIPAIS CONTRIBUIÇÕES DO CURSO DE LICENCIATURA EM EDUCAÇÃO FÍSICA PARA A FORMAÇÃO "TEÓRICO-PRÁTICA" DOS PROFESSORES DAS REDES PÚBLICAS DE ENSINO, QUE INTERFERIRAM POSITIVAMENTE NO SEU EXERCÍCIO PROFISSIONAL}

No momento de proceder à análise dos dados coletados entre os professores inquiridos, verificamos que $10,26 \%$ não cursaram a graduação na FAEFI/UFU, enquanto $89,74 \%$ se formaram nessa faculdade. Entretanto, consideramos que esse dado não interferiu para a realização da pesquisa, uma vez que tal diferença não parece influenciar, significativamente, na análise das representações desses professores, na medida em que, ao apresentar formulações discursivas muito próximas umas das outras, transparece uma formação acadêmica fortemente influenciada pelo mesmo paradigma educacional (tecnicista), tal como oferecido pela FAEFI/UFU.

Baseados nessa afirmação, ao analisar, em primeira instância, quais seriam as principais contribuições dos cursos de LEF para a formação "teórico-prática" dos professores inquiridos, que interferiram positivamente no seu exercício profissional na escola pública, identificamos as seguintes categorias de análise, a saber: Formação FilosóficoPedagógica; Iniciação Esportiva; Jogos Recreativos; Esforço Pessoal; Aulas Práticas; Influência Docente e Estágios e Iniciação Científica.

Por um lado, o conteúdo relacionado à categoria formação "filosófico-pedagógica" aparece em primeiro lugar (22,03\%) para os professores das redes públicas de ensino, como principal contribuição do curso de graduação para o exercício de sua profissão. Por outro lado, os conteúdos relacionados aos temas de iniciação esportiva $(16,95 \%)$ foram indicados pelos professores inquiridos como segunda principal contribuição do curso de graduação para o exercício de sua profissão. Em 
terceiro lugar, com 13,56\% das freqüências encontradas, os professores identificaram o conteúdo associado à disciplina "jogos recreativos".

Interessante observar, que junto aos conteúdos associados à disciplina "jogos recreativos" aparece, também, com 13,56\% das freqüências relativas, o "esforço pessoal" despendido pelos professores durante a sua formação inicial, como principal contribuição dos cursos de LEF, para o exercício de sua futura prática profissional na escola pública.

Em quinto lugar, com uma freqüência relativa de 10,17\%, os professores identificaram como contribuição para a formação inicial, a vivência concreta de "aulas práticas". Também com 10,17\% das freqüências, a "influência de alguns docentes" entre os alunos de graduação é representada pelos inquiridos, ao destacar o compromisso social dos mesmos com o conhecimento, com a escola e com a formação de professores para atuar no magistério.

A próxima categoria mais citada pelos professores inquiridos foi referente aos "estágios curriculares" com $6,78 \%$ das freqüências encontradas. Com o mesmo percentual (6,78\%) aparece, também, em sétimo lugar, o processo de iniciação à pesquisa científica conhecida no meio acadêmico como Iniciação Científica.

\section{REPRESENTAÇÕES DOS EDUCADORES DAS REDES PÚBLICAS DE ENSINO, A RESPEITO DAS DIFICULDADES ENCONTRADAS DURANTE O PERCURSO DE SUA ATIVIDADE ACADÊMICA NO CURSO DE GRADUAÇÃO}

Ao procurar conhecer as representações dos professores, sobre quais seriam as maiores dificuldades de formação "teórico-prática" vivenciadas durante o curso de graduação, que interferiram significativamente no seu exercício profissional na escola pública, são apresentadas, a seguir, as categorias de análise identificadas durante este processo de caráter quantitativo-qualitativo dos dados coletados.

As representações apontadas por 38,78\% dos professores inquiridos, apontam o distanciamento da teoria com a prática como a maior dificuldade vivenciada, durante o período de sua formação no curso de graduação, a interferir diretamente no seu exercício profissional na escola pública.

Os professores inquiridos questionaram a competência dos docentes do ensino superior $(20,41 \%)$ como um dos elementos da forma- 
ção, que interferiu significativamente no seu exercício profissional na escola pública.

Ao estabelecer uma relação direta entre formação política e conhecimento instrumental, os professores citam outra dificuldade encontrada na sua formação inicial, que interferiu significativamente no exercício da carreira docente na escola pública. Referem-se, justamente, ao tipo de formação recebida, a qual é citada em 18,37\% das representações que tratam dessas dificuldades como "formação dentro de uma concepção teórica tecnicista voltada somente para o esporte de rendimento" $(\mathrm{P} 1)$.

E, somada a esse tipo de formação profissional, em $8,16 \%$ das representações, os professores ainda acrescentaram a idéia geral de que o principal fator encontrado na formação inicial, que interferiu, significativamente, no exercício de sua prática profissional na escola pública foi, em síntese, resultado de uma formação inicial insuficiente identificada como "falta de preparo para trabalhar em escola" (P20). Também com $8,16 \%$ das representações, os professores apontaram a falta de recursos de apoio bibliográfico, como um dos elementos encontrados na formação inicial, que também prejudicou a formação teórico-prática para o exercício da profissão.

\section{REPRESENTAÇÕES DOS EDUCADORES DAS REDES PÚBLICAS DE ENSINO, A RESPEITO DAS DIFICULDADES ENCONTRADAS NO INÍCIO DE SUAS ATIVIDADES PROFISSIONAIS NA ESCOLA PÚBLICA}

Ao serem indagados sobre as principais dificuldades que encontraram no início de sua atividade profissional, os professores inquiridos apontaram, principalmente, a falta de recursos materiais disponíveis no contexto escolar $(18,52 \%)$, a deficitária formação inicial $(17,78 \%)$, espaços físicos inadequados para o exercício da sua profissão $(11,11 \%)$, a superlotação das salas de aula $(7,40 \%)$ e as dificuldades de comunicação e inter-relacionamento humano entre os colegas da escola $(6,66 \%)$.

A análise desses resultados demonstra que os professores inquiridos reafirmam dois aspectos centrais interferentes no exercício da carreira docente: Primeiro, que o curso de LEF não os preparou adequadamente para enfrentar o mundo da profissão na escola pública, tal como expressa, por exemplo, P37 quando afirma: "na faculdade não 
fomos preparados para a escola pública". Segundo, a constatação do profundo descaso das políticas públicas e dos governos em exercício para com a Educação, o qual pode ser explicitado quando os professores constatam a falta de condições materiais para trabalhar e a existência de uma estrutura fragmentada da escola e do sistema educacional que pouco valoriza e estimula a organização do trabalho coletivo no cotidiano escolar, por não serem oferecidas condições necessárias para que isso seja efetivado.

Ao comparar os dados, constatamos que as representações associadas a uma deficitária formação inicial passam de 8,16\% para $17,78 \%$ no momento de serem caracterizadas as dificuldades que os professores encontraram na primeira escola pública em que trabalharam. As dificuldades advindas da formação inicial são confirmadas agora com contundentes críticas ao curso de licenciatura, tendo como referência, a experiência profissional adquirida: "Faltou manejo das informações recebidas pela universidade" (P20); "precariedade nas teorias e tendências pedagógicas apreendidas na faculdade" (P3); "faltou embasamento teórico" (P20); "na graduação houve uma ausência de orientações sobre planejamento e diretrizes curriculares de ensino" (P23); "o desconhecimento total da realidade do contexto escolar do ponto de vista profissional" (P8); "a dicotomia que enfrentamos entre teoria e prática na formação acadêmica" (P4), são algumas das falas que sintetizam as representações dos professores a respeito das dificuldades da formação inicial.

\section{SUGESTÕES DOS EDUCADORES DAS REDES PÚBLICAS DE ENSINO, PARAA REFORMULAÇÃO CURRICULAR DO CURSO DE LICENCIATURA EM EDUCAÇÃO FÍSICA}

Uma das questões colocadas para os educadores das redes públicas de ensino inquiridos foi a de apresentar sugestões para transformar o curso de LEF, tendo em vista a superação das dificuldades e dos problemas levantados. Nesse sentido, 32,15\% representações apontam que o curso de licenciatura seja organizado para promover uma formação crítica orientada, de fato, para a realidade escolar, por meio da promoção de uma maior vivência dos estudantes de licenciatura nas escolas públicas. Desses, 32,15\%, 10,72\% consideram fundamental que o curso de licenciatura minimize a dicotomia existente entre teoria apreendida 
e prática do cotidiano escolar, colocando os docentes da graduação e os alunos mais próximos do cotidiano escolar durante o seu processo de formação.

Dentre as sugestões apresentadas, apontam para a necessidade de que a formação do estudante de graduação seja associada à prática da pesquisa no campo da educação. Nesse sentido, P8 é explícito, quando no momento de questionar a falta de formação dos professores para criar/construir conhecimento ao invés de simplesmente reproduzilo, aponta a necessidade de que a formação profissional no campo da Educação Física Escolar "tenha como objetivo a formação do professor pesquisador da sua própria prática pedagógica” (P8).

Das representações encontradas, $21,43 \%$ propõem que as horasaulas dos estágios sejam aumentadas de tal forma que as disciplinas do curso associadas, direta ou indiretamente, à prática docente, fiquem bem mais próximas da realidade da escola pública. Os professores sugerem, também, que os estágios aconteçam em várias escolas e com várias turmas, diferentemente do que em geral ocorre na prática do estágio supervisionado, quando o estudante limita-se a freqüentar somente uma escola e participar das aulas de uma única turma.

Com $10,72 \%$ das freqüências encontradas, é sugerida a contratação de novos docentes, que além de estarem atualizados na prática da pesquisa, tenham vivência de aula nas escolas. Durante o curso, o corpo docente deve apresentar, como norma, os seus programas de disciplina para serem efetivamente discutidos com as turmas e que suas atividades sejam regulamentadas e cumpridas, principalmente no que diz respeito àquilo que será desenvolvido nos conteúdos. Baseados na sua experiência discente, os professores inquiridos lembram que, em vários casos, o que era proposto nas disciplinas não se concretizava durante o semestre letivo.

Finalmente, $46,23 \%$ das sugestões foram relacionadas a aspectos organizativos da estrutura curricular e do ensino superior no curso de licenciatura, as quais foram apresentadas com o intuito de contribuir para que a formação inicial se aproxime da realidade escolar de forma a proporcionar um ensino de qualidade na licenciatura. Uma síntese das sugestões levantadas é apresentada no quadro 1, a seguir: 
Quadro 1. Síntese das sugestões apresentadas pelos professores das escolas públicas inquiridos, para contribuir com a melhoria do curso.

- No início do curso, oferecer aos graduandos uma versão global do curso, as áreas de atuação profissional, bem como as perspectivas de desenvolvimento das mesmas.

- Definir, por meio do curso de licenciatura, as disciplinas mais importantes para se trabalhar na escola e aumentar a carga horária dessas.

- Distribuir a carga horária de forma equilibrada para garantir a participação dos alunos em projetos de ensino, pesquisa e de extensão e outros eventos científicos e culturais da instituição.

- Promover mudanças na ordem das disciplinas teóricas e práticas da grade curricular, de tal forma que sejam organizadas para viabilizar maior coerência e uma distribuição abrangente dos conteúdos propostos no currículo.

- Investir na formação teórica do estudante aumentando, dentre outros aspectos, a quantidade de livros, a atualização das suas edições, bem como a leitura diversificada de literatura relacionada com a área.

- Elaborar e apresentar uma didática específica para a área de Educação Física Escolar que seja capaz de oferecer uma maior interação dos conteúdos técnicos do currículo, com a realidade da Educação Física vivenciada nas escolas públicas.

- Oferecer durante o curso, mais aulas práticas e criativas por parte dos docentes com utilização de materiais alternativos voltados para a área escolar.

Fonte: Pesquisa com professores e professoras realizada neste estudo. 


\section{CONSIDERAÇÕES FINAIS}

Ao analisar as entrevistas dos professores das escolas públicas, várias questões significativas transpareceram no transcorrer desse processo, as quais interferem no seu exercício profissional e, no nosso entendimento, no desenvolvimento da educação pública brasileira. Essas questões foram manifestadas pelos professores, tanto nas representações sobre a forma como compreendem a relação teoria-prática, quanto pela identificação objetiva da falta de aproximação dos próprios docentes de ensino superior com a realidade escolar. Para a maioria dos professores inquiridos, continua a existir descaso dos governos em exercício com a educação pública, caracterizado, principalmente, pela falta de condições materiais e de espaço físico adequado para o exercício da profissão docente.

Somado a isso, para nós, ainda existe falta de vontade política para superar as falhas do sistema educacional, cuja lógica de funcionamento impede, em grande parte, que sejam criadas condições necessárias para que a comunidade escolar possa, com autonomia democrática, buscar a ruptura das fragmentações existentes nos campos da gestão escolar e da hierarquia de saberes disciplinares, historicamente impostos pela racionalidade técnica subjacente à formação escolar e todos os níveis de ensino.

Apesar de reconhecermos que no País há esforço para colocar todas as crianças na escola, ${ }^{1}$ entendemos que a efetivação dos professores na carreira docente mediante a formalização de contratos que estipulam o pagamento de salários pelas horas/aula ministradas, ao invés de se procurar efetivar a sua presença em período integral para que possam dispor de tempo suficiente para participar da construção e monitoramento do projeto político-pedagógico e da proposta curricular das suas escolas, tem limitado, seriamente, a possibilidade de que esses mesmos professores organizem sua prática docente para refletir coletivamente e intervir criticamente nas escolas com a finalidade de contribuir para a tão ansiada melhoria do ensino público. Devemos lembrar aqui que, ao tratar do magistério da Educação Básica, o PNE é claro ao propor na Meta número dois (2) que trata desse assunto, que seja iniciada, imediatamente, a implantação gradual da jornada de trabalho de tempo integral, quando conveniente, cumprida em um único estabelecimento escolar (BRASIL, 2004, p. 36). 
Acrescenta-se a isso, o fato de a situação econômica dos professores de ensino fundamental no País continuar sendo considerada bastante precária. Segundo o relatório da Avaliação Técnica do PNE para o período 2000-2003 (BRASIL, 2004), a média salarial no Brasil era de R\$ 422,00 (U\$ 192,00) para os professores de ensino infantil, $\mathrm{R} \$ 461,67$ da $1^{\mathrm{a}}$ a $4^{\mathrm{a}}$ séries (U\$ 200,00) e de $\mathrm{R} \$ 599,85$ de $5^{\mathrm{a}}$ a $8^{\mathrm{a}}$ séries $^{2}$ (U\$ 261,00) no ano de 2001. Além disso, no final de 2003 era notório o fato de que apesar da necessidade de serem atualizados os Planos de Carreira dos sistemas municipais e estaduais de ensino para melhorar o salário docente muitos ainda não tinham procedido a sua elaboração e aqueles que o fizeram,

não o implementaram nas suas dimensões relativas à progressão horizontal, avaliação de desempenho e estímulo ao aperfeiçoamento docente. Mesmo os salários, que receberam um significativo impacto do FUNDEF em seus momentos iniciais, foram com o tempo desgastados em seu valor, diante das definições de valor mínimo nacional/ano adotadas pelo governo federal (BRASIL, 2004, p. 95).

Em relação às questões associadas à formação profissional, quando iniciamos em 2005 o programa de formação continuada com um grupo de professores da rede pública estadual de ensino, estes expressaram claramente nas inquirições que, fruto de sua experiência profissional, é necessário promover uma formação mais crítica dos estudantes da graduação, associada à prática da pesquisa e a uma maior reflexão teórica sobre a educação e, ainda, de que seja minimizada a ênfase dada à preparação tecnicista (esportiva), orientando-a para atender às necessidades da realidade escolar e os objetivos da escola. Objetivos, dentre os quais, para uma parcela significativa desses professores, não está contemplada a idéia de trabalhar para descobrir e formar talentos e atletas de alto nível, por entender que os objetivos, as condições, a estrutura de funcionamento e o ordenamento legal da Educação Física na escola pública, simplesmente, pouco ou nada tem a ver com esse tipo de propostas "pedagógicas".

Nesse sentido, a idéia de "formar professores e não atletas" nos cursos de graduação representa, claramente, o desejo da maioria desses professores, os quais, diante da experiência vivida no seu exercício profissional mostraram evidências de que é necessário que os cursos 
de licenciatura façam um esforço para superar as suas fragmentações políticas e epistemológicas para assumir, de fato, a tarefa de superar a lógica racionalista e mercadológica que, infelizmente, domina esses cursos de licenciatura. Tarefa esta que, consideramos, não será fácil enfrentar, dada a profunda influência do mundo do esporte competitivo introduzido nas Universidades, por meio, da criação de Centros de Excelência que estão orientados para a formação de talentos esportivos, assim como pela ação do mercado cuja enorme propaganda vem influenciando os estudantes para o exercício profissional no "mundo Fitness" (das academias esportivas). Isso, ao mesmo tempo em que a mídia, as políticas governamentais, os baixos salários e o próprio cotidiano escolar das redes públicas de ensino, servem como fatores desmotivadores e desestimuladores do exercício da profissão docente no ensino básico. Problema este que se encontra presente em todas as modalidades ligadas ao mundo do trabalho educacional.

No que diz respeito aos professores da educação básica, a situação também não é nada alentadora. A profissão professor corre risco de extinção no país. Como praticamente não existem estímulos para procurar essa carreira, o cenário poderá ficar crítico nos próximos 10 anos. Pesquisa da Confederação Nacional dos Trabalhadores em Educação, realizada em 2003, mostrou que $53,1 \%$ dos professores em atividade estavam na faixa dos 40 aos 59 anos, e 38,4\% tinham entre 25 e 39 anos. Só 2,9\% se encontravam na categoria entre os 18 e 24 anos. A pergunta inescapável é: quem vai substituir os atuais mestres à medida que eles forem se aposentando? (FolHa de SÃo PAUlo, 2005, p. A2).

A escassez de docentes já é perceptível em vários Estados do País, em especial em áreas técnicas (física, química e matemática), cuja formação encontra em outras atividades da iniciativa privada, condições profissionais mais convidativas que as oferecidas pelas escolas.

E não se fala apenas de salário, mas também de prestígio. Até algum tempo atrás, professores já ganhavam mal, mas ainda tinham um alto reconhecimento social. A situação é grave e não permite tergiversações. Ou o Brasil decide tornar a educação uma prioridade real, e não apenas uma retórica, ou a falta de educação continuará causando grandes danos ao país (FolHa de São Paulo, 2005, p. A2). 
Identificamos, também, que ao expressar o desejo de que os cursos de licenciatura contribuam para a formação crítica dos estudantes, uma parcela significativa dos professores inquiridos propõem, com clareza, que seja minimizada a distância existente entre teoria e prática durante a formação profissional mediante a oferta de um maior número de horas/aulas, e seja promovida uma interação maior entre os estudantes, os docentes do curso de licenciatura e a realidade do ensino público. De nossa parte, consideramos importante associar a essa proposta, as sugestões encontradas em $10,72 \%$ das proposições identificadas nas inquirições, no sentido de que sejam realizados esforços para que os estudantes dos cursos de graduação tenham acesso à prática de pesquisa pedagógica durante sua formação e aprenda a produzir conhecimento em vez de simplesmente reproduzi-lo.

Para nós, a mudança qualitativa e significativa do currículo, somente será promovida a partir do momento em que este passe a ser tratado pela comunidade numa perspectiva antropológica e sociológica, assumindo, como ponto de partida, o sujeito concreto que viverá a Universidade como um todo e não unicamente o cotidiano do seu curso de graduação.

A Universidade já foi considerada bem público até poucos anos atrás, por entender que sua força radicava na capacidade de inserção nas políticas de construção de um projeto nacional baseado nas perspectivas do desenvolvimento científico-tecnológico e cultural do povo, motivo pelo qual foi adequadamente financiada pelo Estado, pelo menos até o início dos anos 80 do século passado.

Entretanto, especialmente com o advento da globalização neoliberal, tornaram-se fatos, tanto a perda do seu antigo status de produtora exclusiva do conhecimento, quanto a sua relevância no âmbito de influência para a elaboração de políticas públicas. Fatos estes manifestados, dentre outros aspectos, no acirramento das práticas corporativas entre docentes das Universidades, nas constantes ações de descapitalização e de sucateamento vivenciadas desde o final da década de 1980, e, pela emergência do descontrolado crescimento do mercado privado ligado ao ensino superior.

Nessa conjuntura, apesar da resistência manifestada em parte, em inúmeras greves nacionais, as Universidades Públicas brasileiras se viram na obrigação de promover um processo progressivo de privatização por meio da criação de um mercado de serviços que terminou, por sua vez, relacionando-se com as políticas neoliberais, ao mostrar certa semelhança com as deliberações da Organização Mundial 
do Comércio (OMC), a qual se dedicou também a partir da segunda metade da década de 1980, a abolir regras e limites associados à circulação do capital interessado nos investimentos em educação (SANTOS, 2005).

A necessidade de pensar como sair desse quadro de contínuo tensionamento e crise em que se encontra a profissão docente e o sistema educacional público a partir de uma perspectiva contra-hegemônica, já nos fez concordar, inicialmente (MuÑoz PALAFOX; LeÃo, 2004), com o fato de que a vida familiar, a vida na escola, a prática da pesquisa e a militância política, continuam sendo espaços significativos para o desenvolvimento de uma formação crítica orientada para a construção da Omnilateralidade Humana, tal como defendido por Karl Marx e Antônio Gramsci, e de que esse tipo construção exige interesse, persistência, investimento pessoal e compromisso com o projeto de vida pessoal e profissional/político que assumimos para enfrentar as "tensões" e as "dores" da profissão docente (FONSECA, 1997).

\title{
Course Reform in Physical Education B.A Programs: contributions from public school teachers
}

\begin{abstract}
The aim of this article is to analize the new National Syllabus Guidelines for Higher Education and, more specifically, the new process of course reform designed for Physical Education B.A programs. As such, this article aims at contributing to the debate over those guidelines in the context of course reform for these courses, from the starting point of the representations of public school teachers which are related to their knowledge and skills, their initial education, and their professional performance.
\end{abstract}

KEYWORDS: public policies - National Syllabus Guidelines - course syllabus theory - physical education - teacher education

Reforma Curricular de los Cursos de Formácion en Educácion Física: contribuicones de los profesores de las redes públicas de enseñanza

\section{RESUMEN}

El objetivo del este artículo es analisar las nuevas Directrizes Curriculares Nacionales, especialmente, el estudio del proceso de reforma curricular promovido para los cursos de formácion en Educácion Física, asi como contribuir para el debate sobre tales directrizes en el contexto de la reforma de los cursos de licenciatura, a partir del estudio de las representaciones de profesores de las redes públicas de enseñanza, relacionadas con sus saberes a respecto de su formação inicial y de su exercício profissional.

PALABRAS-CLAVE: políticas públicas - Directrizes Curriculares - teoria del currículo - educación física - formación de professores 


\section{NOTAS}

1 Segundo balanço realizado pelo Fundo das Nações Unidas para a Infância (UNICEF) em 2005, hoje mais de 97,0\% dos meninos e meninas de 7 a 14 anos estão matriculados no ensino fundamental. No início da década de 90, quando o Estatuto da Criança e do Adolescente (ECA), foi criado, mais de 10,0\% das crianças brasileiras estavam fora da escola (FolHa de SÃo PaUlo, 2005, p. A2). Esse mesmo balanço indica que, apesar dos números mostrarem que crianças e adolescentes estão matriculados na escola, o desafio é oferecer qualidade. Os problemas são mau rendimento, evasão escolar, professores com pouco preparo e escolas mal equipadas (Folha de São Paulo, 2005, p. A2).

2 Na região sudeste, que inclui o Estado de Minas Gerais, o relatório da Avaliação Técnica do PNE para o período 2000-2003, informa que a média salarial no Brasil era de $\mathrm{R} \$ 522,44$ para os professores de ensino infantil, $\mathrm{R} \$ 599,19$ da $1^{\mathrm{a}}$ a $4^{\mathrm{a}}$ séries e $\mathrm{R} \$ 792,82$ de $5^{\mathrm{a}}$ a $8^{\mathrm{a}}$ séries.

\section{REFERÊNCIAS}

BRASIL. Avaliação técnica do Plano Nacional de Educação. Brasília: Câmara dos Deputados, 2004.

BRASIL/CNE/CES. Histórico do processo da elaboração das diretrizes curriculares nacionais para os cursos graduação em educação física. 2004. Disponível em: <www.cev.org.br/diretrizesef2004/historia.htm Acesso em: 2 out. 2004.

FONSECA, S. G. F. Ser professor no Brasil: história oral de vida. Campinas: Papirus, 1997.

MUÑOZ PALAFOX, G. H.; LEÃO, E. Resiliência na Educação: desafios e possibilidades de sobrevivência do educador no século XXI. Educação em Ação. Formação de Professores para o Século XXI, Patrocínio, ano 1, n. 1, p. 25-49, jul./dez. 2004.

SANTOS, B. de S. Entrevista realizada na Universidade Federal de Minas Gerais. Disponível em: <http://www.ufmg.br/online/arquivos/001509.shtml>. Acesso em: 10 nov. 2005. 
TAFFAREL, C. N. Z.; LACKS, S. Diretrizes curriculares: proposições superadoras para a formação humana. In: FIGUEIREDO, Z. C. (Org.). Formação profissional em Educação Física e mundo do trabalho. Vitória: Gráfica da Faculdade Salesiana, 2005.

FOLHA DE SÃO PAULO, São Paulo, 3 out. 2005. Editorial, p. A2.

Recebido: 22 de março de 2006 Aprovado: 8 de abril de 2006

Endereço para correspondência: Rua A, Qd. B, Lotes 03/07, n. 60, Condomínio Vila Rica Apto. 1609, Bl. B, Setor Leste Vila Nova Goiânia - Goiás CEP 74645-210

A/C: Régis Henrique dos Reis Silva

E-mails: regishsilva@universia.com.br

proreitoria@proex.ufu.br 